\title{
Home cage feeding time controls responding under multiple schedules
}

\author{
ALFRED V. BACOTTI \\ University of Maryland, College Park, Maryland 20740
}

\begin{abstract}
Eleven rats were exposed to a multiple variable-interval 1-min variable-interval 1 -min schedule of reinforcement. All rats were initially fed a daily ration of food in the home cages immediately after the end of each session. In a later phase of the experiment, the same amount of food was fed $1 \mathrm{~h}$ after the end of each session. Later, five rats were again fed immediately after each session. Amount of food received and deprivation level in terms of percent of free feeding weight were constant across conditions. Response rates decreased within each session under immediate feeding. When feeding was delayed, rates in each component of the multiple schedule increased throughout the session and the decreasing trends were generally eliminated. The results suggest that home cage feeding time, apart from changes in deprivational level, is an important variable in the control of behavior in experimental sessions.
\end{abstract}

The point of departure for this study was a reliable decrement in responding towards the end of a session in several experiments performed in this laboratory. In order to eliminate this type of within-session trend, the time at which subjects were fed in the home cage was changed (Gollub, personal communication). This manipulation proved effective in maintaining a uniform rate throughout the session. In view of this effect, and since supplemental feeding in the home cage is an ubiquitous aspect of laboratory procedures, a more controlled study of home cage feeding time was initiated.

There seems to be no information available on the effects that changes in feeding time might have on food maintained responding during a session. Finger, Reed, Starling, and Weasner (1960) found that nonreinforced running increased for a group of rats fed immediately after the session. Running did not change for a group of rats when feeding was delayed for $1 \mathrm{~h}$. Using different rats in each condition, Finger et al. showed that behavior during a session could be affected by home cage feeding.

\section{METHOD}

\section{Subjects}

Rats $190,191,192,193,194$, and 195 were male albino Wistar rats, approximately 4 months old and naive at the start of the experiment. These subjects were maintained at $80 \%$ of their unrestricted feeding weights. The weights ranged between 283 and $299 \mathrm{~g}$ at $80 \%$ deprivation.

Rats $222,224,225,226$, and 228 were adult hooded retired breeders with a history of exposure to multiple extinction and variable-interval schedules. These subjects were maintained at $75 \%$ of their unrestricted feeding weights. At this deprivation level weights ranged between 450 and $597 \mathrm{~g}$. Water was available at all times in the home cage for all subjects.

\section{Apparatus}

Each of the two experimental spaces consisted of a Plexiglas

The author wishes to thank Drs. J. E. Barrett and L. R. Gollub for their comments and Ms. S. M. Bacotti for technical and secretarial assistance. Reprints may be obtained from the author at the Worcester Foundation for Experimental Biology Shrewsbury, Massachusetts 01545. and aluminum rat chamber with a grid floor which measured $23.2 \times 20 \times 19.5 \mathrm{~cm}$. All chambers were placed in sound attenuating ice chests and were located in a room supplied with white noise, isolated from programming and recording devices. Each ice chest also contained a ventilation fan.

Experimental Chamber 1. On the front aluminum wall, a Gerbrands pigeon key requiring a force of $0.11 \mathrm{~N}$ to operate was located $2.5 \mathrm{~cm}$ from the floor and $2.2 \mathrm{~cm}$ from one side. The key was transilluminated white by a $2-W$ light. An opening for a feeding cup measuring $4.5 \times 4.5 \mathrm{~cm}$ was located $1.5 \mathrm{~cm}$ from the floor and $8 \mathrm{~cm}$ from either side. One $2-W$ white light was located $14 \mathrm{~cm}$ from the floor and $10 \mathrm{~cm}$ from either side. On the rear wall, one $2-W$ amber light was located $14 \mathrm{~cm}$ from the floor and $10 \mathrm{~cm}$ from either side. Programming and recording functions were arranged by solid state circuitry.

Experimental Chamber 2. On the front wall of this chamber, a bar measuring $5 \times 2.5 \times 1 \mathrm{~cm}$ and requiring a force of $0.20 \mathrm{~N}$ to operate was located $2.5 \mathrm{~cm}$ from the floor and $7.5 \mathrm{~cm}$ from one side. A feeding cup measuring $5 \times 3.5 \times 2 \mathrm{~cm}$ was located $2.5 \mathrm{~cm}$ to the right of the bar and $2 \mathrm{~cm}$ from the floor. Three white 2-W lights were mounted on the front and rear walls of the chamber. These were located $2.5 \mathrm{~cm}$ from each side, $14 \mathrm{~cm}$ above the floor, and spaced $7.5 \mathrm{~cm}$ apart. Only the center light on the rear wall and the two side lights on the front wall were operational. Programming and recording were done by solid state circuitry.

\section{Procedure}

Rats $190,191,192,193,194$, and 195 were studied in Chamber 1 . The keypress response was initially shaped by the method of successive approximations. Subsequently, each response was reinforced (FR1) for 60 responses on each of 2 consecutive days. All other rats were studied in Chamber 2 . The barpressing response by these rats had previously been shaped. Deprivation levels for all rats were initially maintained by feeding fixed amounts of Purina Laboratory Chow in the home cage after the end of each experimental session. The fixed amount of food was determined empirically for each subject prior to experimentation. The weight of food to the nearest gram was varied until a constant amount was determined which when fed daily maintained each rat at its deprived weight. The specific amount varied among rats.

Sessions lasted one hour. Five-minute components of the multiple schedule, each correlated with an arithmetic variable interval 1-min (VI 1-min) schedule of reinforcement alternated successively. Keypressing and leverpressing produced one $45-\mathrm{mg}$ Noyes food pellet on the average of once a minute. In Chamber 1 , Component $1\left(S_{1}\right)$ was associated with the key and the house light on the rear wall lighted; Component $2\left(S_{2}\right)$ was associated with a totally dark chamber. In Chamber $2, S_{1}$ 
Table 1

Number of Sessions of Exposure to Each Feeding Condition for All Rats

\begin{tabular}{cccc}
\hline Rat & Immediate & Delayed & Immediate \\
\hline 190 & 17 & 22 & \\
191 & 17 & 16 & \\
192 & 17 & 22 & \\
193 & 15 & 16 & \\
194 & 15 & 22 & \\
195 & 15 & 22 & \\
222 & 22 & 26 & 29 \\
224 & 30 & 22 & 20 \\
225 & 27 & 24 & 23 \\
226 & 29 & 21 & 21 \\
228 & 26 & 27 & 43 \\
\hline
\end{tabular}

consisted of two front lights on, $\mathrm{S}_{2}$ with front lights off. The light mounted on the rear wall was on during the entire session.

Under all conditions, rats were removed from the experimental chambers within 2 min of the end of each session. During the immediate feeding condition, rats were removed from the experimental chamber, weighed, and placed in the home cage with their daily ration of laboratory chow. During the delayed feeding condition, the procedure after each session was the same, except that the daily ration of food was given $1 \mathrm{~h}$ after the rats had been returned to the home cage.

All rats were exposed first to the immediate feeding condition and then to the delayed feeding condition. The immediate feeding condition was subsequently reinstated for the hooded rats.

Table 1 presents the number of sessions of exposure under each condition for all subjects. Sessions were conducted the same time each day, seven days a week.

\section{RESULTS}

The data are presented in Figure 1 in terms of response rates in each component of the multiple schedule for all conditions. Response rates were calculated by dividing the number of responses emitted in each component during a session by the total time each component was in effect $(30 \mathrm{~min})$. The histograms in Figure 1 are based on the means of the last five sessions at each condition. The filled histograms represent rates when feeding was delayed $1 \mathrm{~h}$; the open histograms represent rates when feeding occurred immediately after each session.

These data show that rates in each component $\left(S_{1}\right.$ and $S_{2}$ ) were higher when feeding was delayed. When immediate feeding was reinstituted for the hooded rats, rates in each component were again lower than under delayed feeding conditions. These effects of home cage feeding were consistent for all rats. The percent increase (absolute increase under delayed feeding, calculated with respect to the preceding immediate feeding condition) ranged between $20 \%$ and $150 \%$.

Figure 2 presents representative cumulative records selected from the last session under each condition. Records from two of the Wistar rats (190 and 192) and two of the hooded rats (222 and 225) are represented. Component 2 is marked by the downward deflection of the event pen. The cumulative recorder reset with each change of components. Each downward deflection of the response pen designates the delivery of food.

Decreasing trends in response rate over the course of the session under the immediate feeding condition are apparent. The decrease was most noticeable within the last few components of a session. Rates increased under the delayed feeding condition, and the abrupt decreases in rates at the end of each session under immediate feeding were generally eliminated. The increases in responding were not, however, confined to the final few minutes of each session. As seen under the delayed feeding condition, rates throughout each session were generally increased.

Body weights measured before each session and amount of food fed in the home cage measured to the nearest gram during the last 5 days under each condition were analyzed. These data are not presented, since variation in body weight never exceeded $4 \mathrm{~g}$, and variation in amount of food presented in the home cage never exceeded $3 \mathrm{~g}$ for any rat. Differences in both measures between delayed and immediate conditions were typically less than these values.

\section{DISCUSSION}

The immediate home cage feeding of rats following an experimental session decreased rates toward the end of the experimental period. Subsequently delaying home cage feeding $1 \mathrm{~h}$ increased responding in both components of the multiple schedule. Although changes in the time of home cage feeding exerted the greatest
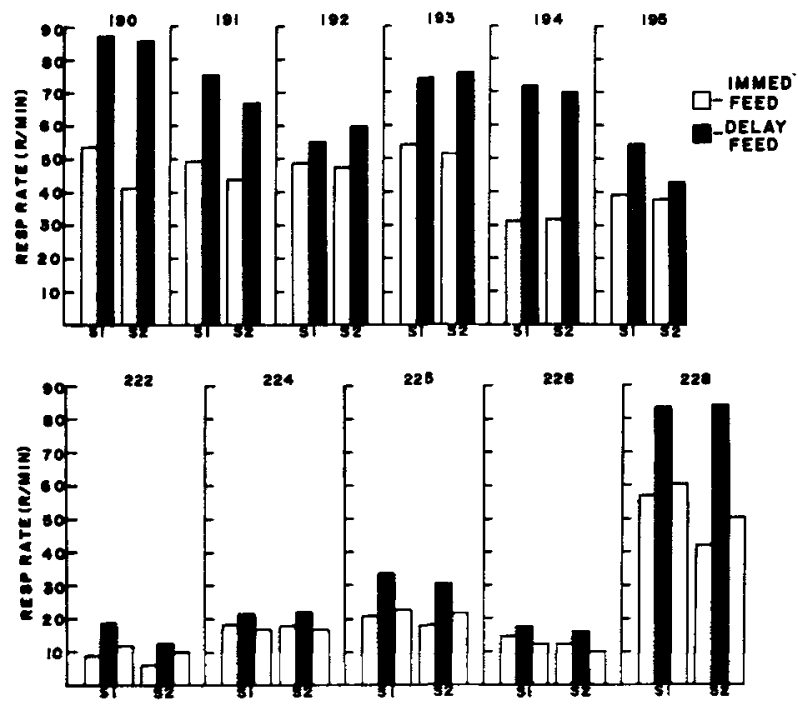

Figure 1. Response rates (responses per minute) for each rat under each feeding condition. $S_{1}$ and $S_{2}$ refer to the components of the multiple schedules. Open histograms represent rates when home cage feeding was immediate after each session and filled histograms represent rates when feeding was delayed $1 \mathrm{~h}$. Numbers above each histogram indicate individual rats. 


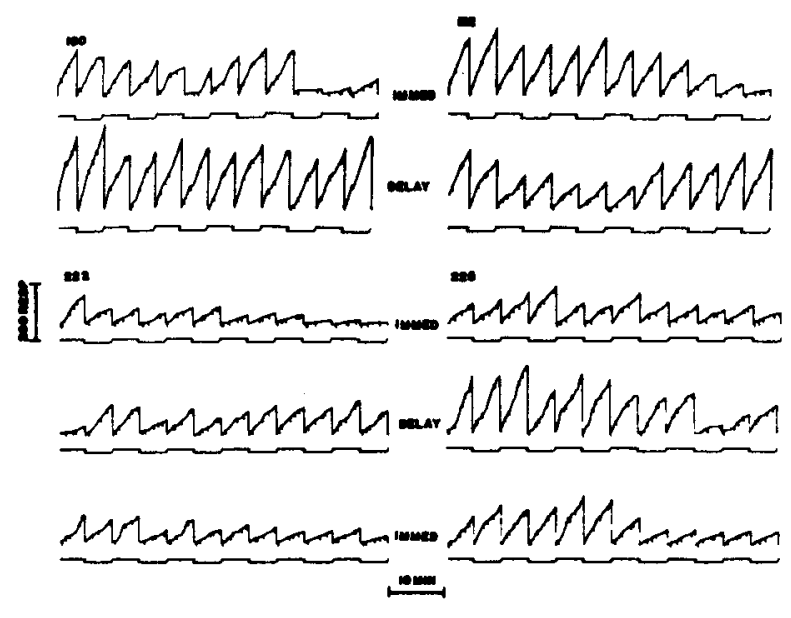

Figure 2. Cumulative response records for four rats (190, 192,222 , and 225) from the last sessions of immediate and delayed feeding conditions. Cumulative responses are shown on the ordinate and time on the abscissa. Diagonal marks on the response pen indicate food delivery. The response pen reset and the event pen offset with each change of components in the multiple schedule.

influence during the last few minutes of each session, the effect was not limited exclusively to the end of each session. General increases in rates over the entire session were evidenced in the cumulative records. Since a constant body weight was maintained, and since the amount fed after each session did not vary appreciably, the rate changes could not be attributed to changes in deprivation level.

When feeding was delayed $1 \mathrm{~h}$, the total number of hours between presentation of food in the home cage and the start of the next experimental session decreased from 23 to $22 \mathrm{~h}$. Decreases in hours of deprivation have been found to decrease rates (Carlton, 1961; Clark, 1958). Since the opposite effect was obtained in the present experiment, total hours between food presentation in the home cage and the beginning of the next session is probably not the main variable determining rate changes. The effects observed were independent of changes in deprivation conditions. The main variable was whether or not home cage feeding occurred immed. iately after the session.

The results reported here are the opposite of those reported by Finger et al. (1960) for wheel running. These authors found increases in wheel running when rats were fed immediately after each session. One major distinction exists between this study and the present investigation. In the present study, food was made contingent on responding during the experiment. In spite of this difference, the explanation offered by Finger et al. that immediate home cage feeding reinforced behavior during the session can not apply to the present results where a decrease in rates was found under immediate feeding.

An adequate account of the present data can be made by considering home cage feeding as the presentation of some amount of response-independent reinforcement. Response-independent reinforcement decreases rates when presented successively in multiple schedules (Nevin, 1974) or concurrently (Rachlin \& Baum, 1972) within a session. The present data would be consistent with an interpretation of home cage feeding as response independent reinforcement, with the rate decreasing effects weakened as the time between the response-produced food (experimental session) and response-independent food presentation periods increased. Viewed in this way, the experimental session may be considered as one component of a multiple schedule and the home cage as another component.

Several studies (Estes, 1943, 1948; Walker, 1952; Herrnstein \& Morse, 1957; Bower \& Kaufman, 1963 Henton \& Brady, 1970) have indicated that stimuli paired with response-independent food increases response rates when they are superimposed on response independent schedules of reinforcement or during the extinction of previously conditioned responding. Conceivably, stimuli were available in the present study at the end of each session. The stimuli may reliably have preceded the delivery of response-independent food in the home cage when feeding was immediate. The factors controlling the direction and magnitude of response rate changes during stimuli which precede response-independent food presentation are varied. For example, Smith (1974) has shown that brief duration stimuli $(5 \mathrm{sec})$ preceding response-independent food presentation increased rates, but longer durations decreased rates. As indicated in Figure 2 of the present study, low rates were especially evident during the final $15 \mathrm{~min}$ of eacis session when feeding was immediate. This suggests that the stimuli at the end of each session were effectively longer than most of the studies which have shown rate increasing effects of stimuli which precede response independent food delivery.

Smith (1974) also reported that the baseline frequency of reinforcement maintaining behavior and the absolute response rate determine the magnitude and direction of rate changes. At least two studies which reported increases in rates with prefood stimuli established low baseline rates by differentially reinforcing long interresponse times (Herrnstein \& Morse, 1957; Henton \& Brady, 1970). Additionally, the magnitude and direction of rate changes may be influenced by the magnitude of the response-independent food relative to the amount of food presented contingent on a response. In the present study, food in the home cage represented a substantially greater percent of total daily food diet than did food during the experimental session. These variables, however, remain to be investigated in the context of home cage feeding.

The present data indicate that behavior in the experimental chamber cannot be isolated from events that occur outside the experiment. The data are also relevant to a consideration of experimental variability. The 
experimental analysis of behavior is often concerned with achieving a consistent level of responding in daily sessions in order to assess the effects of a given variable on steady state performance. It is clear from the present data that even a moderate change in the time of feeding following experimental sessions can increase or decrease rates. The changes in feeding regimen reported in the present study typically produced changes in rates within a session or two. These nearly immediate effects suggest that more stringent control over home cage feeding may eliminate, at least in part, some of the day to day variability often found in behavioral baselines. These data also provide an empirical basis for a common laboratory procedure. Delayed feeding generally eliminated the decrease in rates toward the end of each session that was present when home cage feeding was immediate; when immediate feeding was reinstituted, these trends reappeared.

The relevance of home cage feeding as an important experimental variable cannot be reliably established without further investigation. Further research should be concerned with: (1) demonstrating parametrically the effects of delayed feeding by manipulating systematically the delay time, (2) demonstrating this effect in species other than rats, and (3) employing different schedules of reinforcement in order to assess the effects of changes in home cage feeding on differentially maintained behavior.

\section{REFERENCES}

Bower, G., \& Kaufman, R. Transfer across drives of the discriminative effect of a Pavlovian conditioned stimulus. Journal of the Experimental Analysis of Behavior, 1963, 6, 445-448.

Carlton, $P$. L. The interacting effects of the deprivation and reinforcement schedule. Journal of the Experimental Analysis of Behavior, $1961,4,379-381$.

Clark, F. C. The effect of deprivation and frequency of reinforcement on variable-interval responding. Journal of the Experimental Analysis of Behavior, 1958, 1, 220-228.

Estes, W. K. Discrimination conditioning I. A discriminative property of conditioned anticipation. Journal of Experimental Psychology, 1943, 32, 150-155.

Estes, W. K. Discrimination conditioning II. Effects of a Pavlovian conditioned stimulus upon a subsequently established operant response. Journal of Experimental Psychology, 1948, 38, 173-177.

Finger, F. W., Reid, L. S.. Starling, L., \& Weasner, M. H. Activity changes as a function of reinforcement under low drive. Journal of Comparative and Physiological Psychology, 1960, 53, 385-387.

Henton, W. H., \& Brady, J. V. Operant acceleration during a pre-reward stimulus. Journal of the Experimental Analysis of Behavior, 1970, 13, 205-209.

Herrmstein, R. J., \& Morse, W. H. Some effects of response independent positive reinforcement on maintained operant behavior. Journal of Comparative and Physiological Psychology, 1957, 50,461-467.

Nevin, J. A. Response strength in multiple schedules. Journal of the Experimental Analysis of Behavior, 1974, 21, 389-408.

Rachlin, H., \& Baum, W. M. Effects of alternative reinforcement: does the source matter? Journal of the Experimental Analysis of Behavior, 1972, 18, 231-241.

Smith, J. B. Effects of response rate, reinforcement frequency, and the duration of a stimulus preceding response-independent food. Journal of the Experimental Analysis of Behavior, $1974,21,215-221$.

Walker, $\dot{K}$. C. The effect of a discrimination stimulus transferred to a previously unassociated response. Journal of Experimental Psychology, 1942. 31, 312-321.

(Received for publication January $28,1975$. Revision accepted June 12, 1975.) 